\title{
Multicorporalidad frente a ocularcentrismo: de la ciudad ojo-individuo a la ciudad sensorial-participada
}

\author{
Laura Moya Santander ${ }^{1}$; José Ángel Bergua Amores²; Marcos Ruiz Pérez ${ }^{3}$
}

Recibido: 25 de junio de 2018 / Revisado: 05 de julio de 2018 / Aceptado: 28 de enero de 2019

Resumen. Algunos autores/as, como Jay (1988, 2003, 2007, 2008), Levin (1988, 1993) o Jenks (1995), han investigado acerca de la influencia del ocularcentrismo en la cultura occidental. Otros/as, como Pallasmaa (2006), han especificado esta influencia en el ámbito arquitectónico y urbanístico. Finalmente, a partir de la década de los ochenta, la antropología sensorial cuestionó el visualismo del pensamiento y cultura occidentales, haciendo hincapié en trascender este sesgo con el fin de conectar con la experiencia cultural de los sujetos no occidentales. Sin embargo, y atendiendo a los avances en esta última disciplina, las taxonomías de los sentidos en las culturas responden a un orden cultural y social determinado por la asignación de mayor o menor valor a nuestros sentidos. ¿Y si cuestionamos dicha taxonomía ocularcéntrica dentro de nuestra propia cultura occidental, valiéndonos de las experiencias de los cuerpos que resisten a dicha jerarquización?

En este artículo se analiza cómo se gestó el ocularcentrismo en la Modernidad y cómo continúa siendo el principal paradigma en la construcción de las ciudades. Más tarde, atendiendo al desmontaje de dichas taxonomías de la mano de la antropología sensorial y utilizando la multiplicidad de tecnologías que en nuestro tiempo permiten la sinestesia e interdependencia de los sentidos, se presenta un proyecto multisensorial para habitar la ciudad. Este proyecto tiene por objetivo facilitar a los participantes habitar los espacios urbanos de maneras diversas, alejadas de las formas normalizadas de interacción.

Palabras clave: ocularcentrismo; ciudad; sentidos; cuerpo; diversidad

[en] Multicorporality against ocular-centrism: from the visual/individual city to the sensory/participative city

\begin{abstract}
Certain authors, such as Jay (1988, 2003, 2007, 2008), Levin (1988, 1993) and Jenks (1995), have investigated the influence of ocular-centrism in Western culture. Others such as Pallasmaa (2006) have specifically considered this influence in the architectural and planning context. Finally and since the 1980s, sensory anthropology has questioned the visualism of Western thought and culture, emphasising a need to transcend this bias in order to connect with the cultural experience of non-Western subjects. However, and taking into account the advances of the latter field, cultural taxonomies of the senses follow a cultural and social order that is determined by the assignment of greater or lesser value to our senses. But we may use the experience of bodies that resist this hierarchical process to question the ocularcentric taxonomy present in our own Western culture.

This article analyses how ocular-centrism was managed in modernity and how it remains the main paradigm in the construction of the cities. The paper then presents a multisensorial project for inhabiting cities based on the dismantling of said taxonomies through sensory anthropology, making use of the range of contemporary technologies that permit synaesthesia and the interdependence of our senses. The aim of this project is to enable participants to inhabit urban spaces in diverse ways that differ from the normalised forms of interaction.
\end{abstract}

Keywords: ocular-centrism; city; senses; body; diversity

Sumario: Introducción. 1. El ojo desencarnado y la supresión de la corporalidad. 2. Ocularcentrismo en la arquitectura y el planeamiento urbano. 3. Multicorporalidad y sinestesia de los sentidos. 4. Una acción multisensorial en la ciudad. 5. Conclusión. 6. Referencias bibliográficas.

\footnotetext{
Universidad de Zaragoza, España

lmoya@unizar.es

2 Universidad de Zaragoza, España

jabergua@unizar.es

3 marcosrp94@gmail.com
} 
Cómo citar: Moya Santander, L.; Bergua Amores, J. A.; Ruiz Pérez, M. (2020) Multicorporalidad frente a ocularcentrismo: de la ciudad ojo-individuo a la ciudad sensorial-participada, en Cuad. trab. soc. 33(1), 127-140.

\section{Introducción ${ }^{4}$}

Lo participativo es un concepto cada vez más presente en las sociedades de este siglo, aunque realmente su empuje comenzó en las últimas décadas del siglo pasado. Es el caso de la política, donde la participación viene insistiendo en el corazón de las democracias avanzadas, desde los núcleos de intervención participativa (Dienel y Harm, 2001), ideados en Alemania allá por los 1970, hasta los presupuestos participativos que Portoalegre comenzó a ensayar en los años 1980 (Genro y Souza, 2000), pasando por el asambleísmo de los nuevos movimientos sociales y el reconocimiento en la alta política del derecho a decidir en un amplio abanico de asuntos. Igualmente es el caso de la investigación social, tanto con la Investigación Acción Participativa (o PAI si subrayamos más todavía la participación) (VV.AA. 1995) o las variantes de Análisis Institucional (Hes y Savoye, 1988), además de la clásica observación participante.

La participación no solo es importante en la investigación, incorpore o no la intervención, sino que es cada vez más importante en la propia intervención social e, incluso, ineludible en alguna de sus modalidades, como la acción comunitaria ${ }^{5}$ (Marchioni, Morin y Álamo, 2013). Igualmente está presente en cierto arte contemporáneo que, habiendo desbordado algunas de sus características principales, ha desembocado en el "fin del arte" (Danto, 2012). Es lo que ha ocurrido cuando se ha deshecho el esquema autor/espectador (Rancière, 2008), se combinan o directamente se olvidan los soportes tradicionales e, igualmente, cuando se estimulan respuestas colectivas (Laddaga, 2010; Bourriaud, 2006), gran parte de ellas participadas. Tampoco hay que olvidar la presencia de la participación en el diseño de productos y espacios (Assaro, 2000), la creciente importancia del marketing participativo (que aprovecha el viejo hábito del boca-a-boca), la inteligencia colectiva que encontramos en internet (Rheingold, 2002), el procomún colaborativo (Rifkin, 2014) - tanto el tradicional como el actual (Hess y Ostrom, 2011)- , las redes de intercambio de distintas clases de bienes y servicios que funcionan al margen de la lógica del capital, etc. Por otro lado, la participación no solo ha disuelto, en cada uno de los ámbitos mencionados, la distinción jerárquica entre élites y gentes, sino que las propias distinciones funcionales de ámbitos también han saltado por los aires. Es lo que ocurre, por ejemplo, cuando confluyen la política, las artes y la investigación (Laister y Lipphardt, 2015). Finalmente, tampoco conviene olvidar que lo participativo, no solo es un instrumento cada vez más apetecible en las políticas públicas y la investigación social, a veces en alianza con el marketing, el arte, etc., para gestionar más eficazmente el orden, pues también está presente, quizás desde siempre, en un amplio abanico de prácticas resistentes o instituyentes ${ }^{6}$.

La causa de la gran presencia que ha alcanzado el hábito participativo en múltiples campos bien podría tener que ver con la razón epistemológica que desgranara Ibáñez (1985). Por un lado, partía del hecho de que la investigación social forma parte de un estilo de autoinstitución heterónomo o jerárquico por el que las élites políticas y económicas encargan a las élites científicas que produzcan conocimiento acerca de las gentes, con la intención de usarlo para emprender acciones que también tomarán a las gentes como objeto. Por otro lado, este estilo de autoinstitución se caracteriza por el hecho de que acompaña a procesos de incremento de complejidad del orden, logrado con la liberación de distintos componentes de la

\footnotetext{
4 Agradecemos al colectivo mundoCRIP todo el tiempo compartido en estos años, los talleres, las sesiones de trabajo, las acciones ¡y las que todavía quedan!

Nos referimos al concepto de acción comunitaria tal y como lo plantean Llena y Úcar (2006), entendiéndolo como un tipo de acción social, de un marco conceptual amplio, polisémico y diversificado que ni es el ámbito de la especialización ni el sujeto/sujeto de estudio de una profesión o disciplina concreta de lo social. Es, por lo tanto, la acción comunitaria, un "crisol diversificado de enfoques, perspectivas y contenidos y (...) un cruce o punto de encuentro de diferentes teorías, prácticas y tradiciones tanto disciplinares como profesionales" (Llena y Úcar, 2006, p. 19).

6 Un magnífico ejemplo de esto es el "artivismo" del movimiento de los trabajadores sin tierra (MST) brasileño en alianza con intervenciones artísticas en la línea del arte relacional de Bourriaud (2006). Téngase además en cuenta que el Movimiento de los trabajadores sin tierra aporta un importante componente místico (Flynn, 2016).
} 
sociedad, que, sin embargo, las élites políticas, en alianza con las científicas, intentan controlar y reducir a base de investigación científica y decisiones políticas o económicas para que el orden no se les vaya de las manos.

Precisamente las distintas perspectivas de la investigación han ido apareciendo e incrementando su potencia, a medida que se liberaban diferentes partes o componentes que, si bien aumentaban la complejidad, también producían un mayor y peligroso montante de incertidumbre, lo cual exigía investigaciones e intervenciones de las élites cada vez más sofisticadas para asegurar el (su) orden frente a ese riesgo. Así, en un primer momento se liberaron los individuos (tanto en el ámbito político - con el reconocimiento de derechos civiles y políticos- como en el económico con la liberación de la fuerza de trabajo-), lo cual exigió la puesta en marcha de las técnicas encuadradas en la perspectiva distributiva (cuya técnica emblemática es la encuesta estadística), acompañadas por intervenciones y decisiones políticas, también centradas en los individuos. Luego, le tocó el turno a los grupos (a nivel político con el reconocimiento de derechos colectivos y en el plano económico al reconocer la importancia de las relaciones grupales, tanto en el ámbito de la producción como en el del consumo), que necesitaron ser investigados con las técnicas de la perspectiva estructural (como el grupo de discusión). Más tarde entraron en escena los contextos culturales (con el multiculturalismo en la política, la importancia de los valores o éticas en la producción y las marcas asociadas a altas cualidades espirituales en el consumo), hacia los que se volcaron las técnicas encuadradas en la perspectiva contextual (como la observación participante o las historias de vida). Finalmente, se liberaron subsistemas capaces de cambio a base de participación y autopoiesis (en los ámbitos mencionados más arriba) que urgieron la intervención de técnicas encuadradas en la perspectiva dialéctica.

Por lo tanto, la participación es hoy el instrumento que sirve para la investigación y el consiguiente control de un modo parecido, aunque en un nivel de complejidad muy superior, a como antaño sirvieron los individuos, los grupos y las (sub)culturas. Dicho de otro modo, la liberación de la participación es el modo como los órdenes sociales contemporáneos garantizan su autoinstitución en términos heterónomos o de dominación. $\mathrm{O}$ sea, el dominio, después de haber utilizado otros medios, en la actualidad, aunque resulte paradójico, logra efectuarse a base de participación (Demo, 2009; Bergua, 2011). De aquí emerge un escepticismo similar al que el propio Ibáñez mostró respecto al grupo de discusión (otra técnica que prometía lo contrario de lo que hacía) y al que otros han manifestado respecto a las técnicas antropológicas (Tyler, 1911).

Aunque en este artículo nos adherimos convencidos al habitus participativo que late en gran parte de la actividad experta contemporánea, también creemos que es necesario tener en cuenta las limitaciones que acabamos de exponer, derivadas de los usos que suele recibir y de las epistemologías que fundamentan los ámbitos funcionales que la acogen. Precisamente, teniendo bien presentes tales límites, emprendimos una modesta investigación-acción que, incorporando la participación, se propuso estimular un habitar corporalmente diverso. Lo realizamos el año 2016, en Zaragoza, formando parte del colectivo Mundocrip. Parte de la intervención se incluyó en el Trabajo de fin de Grado que uno de nosotros presentó con éxito para obtener su Grado en Ingeniería de Diseño (Ruiz Pérez, 2016) y que más adelante resumiremos.

Dicha intervención se apoyó en dos pilares que desgranaremos en los siguientes epígrafes. Por un lado, desde un punto de vista teórico, partimos del carácter multisensorial de la existencia individual y colectiva, esquivado y mutilado desde profundos pilares de la civilización occidental, que a diario reproducen e intensifican el encierro de los cuerpos en un restringido abanico de sentidos y sensaciones. Por otro lado, para realizar la vocación multisensorial de los cuerpos y esquivar el encierro al que son condenados algunos de sus sentidos y sensaciones, también usamos, en el plano metodológico, como criterio de intervención, el "diseño universal" (Design for All) (Holm, 2006), con el que se intenta no la adaptación del sujeto a un entorno, sino al revés. En nuestro caso, utilizamos como instrumento el hackeo urbano (Urban Hacking) (Di Siena, 2011) cuya finalidad es practicar un "urbanismo de código abierto" para intervenir en un entorno ya dado con la intención de cambiar sus funciones, significados y propiedades. Todo ello, incorporando en varios pasos la participación, piedra angular del flanco metodológico de nuestro experimento, a pesar de sus limitaciones. 


\section{El ojo desencarnado y la supresión de la corporalidad.}

En nuestra cultura, el predominio de la mirada frente al olfato, el gusto, el tacto y el oído ha propiciado el empobrecimiento de las relaciones corpóreas (Luce Irigaray, 1978).

Los sentidos son interactivos, no meros receptores pasivos. Sin embargo, como consecuencia de ciertos procesos de jerarquización, pueden entrar en conflicto (Howes, 2014). Antes de dicha jerarquización, hay una completa interacción de experiencias, una situación de "sinestesia" que McLuhan (1985) interpreta en términos de tactilidad. Estamos ante un modo de interacción que nada tiene que ver con el que estimula la segmentación de los sentidos corporales, pues constantemente se traducen unos a otros y son interdependientes. Sin embargo, si se introduce una tecnología en una cultura que da ascendencia a uno u otro de nuestros sentidos, la interrelación se rompe y el sentido dominante puede anestesiar al resto.

Diversas innovaciones tecnológicas han provocado ya importantes cambios en las percepciones. En concreto, como recuerda McLuhan (1985), nuestra civilización ha pasado de disponer de una cultura de carácter más bien táctil a tener otra, basada, no solo en la visión sino en una visión reducida y linealizada por la escritura, una vez que ese medio de comunicación se generalizó después de la imprenta. Dicho de otro modo, el sujeto oral, analfabeto, tribal y mítico cuyo mundo es implícito, simultáneo y continuo, debido a que experimenta en términos sinestésicos, fue sustituido por otro alfabetizado, racional e inscrito en otras tramas sociales como consecuencia, entre otros cambios, del ascenso del sentido visual. En definitiva, no es solo que la cultura oral haya sido encerrada en la palabra escrita para pasar a ser cultura impresa (Pallasmaa, 2006), sino que el ascenso de la visión y el dominio del resto de sentidos han transformado radicalmente el mundo.

Aunque es cierto que el alfabeto fonético ya había reducido la percepción al sentido visual, en la edad de oro del manuscrito no fue capaz de separar del todo lo visual de lo táctil. Esto solo ocurrió con la producción en masa de letras y textos uniformes y repetibles que se impulsó con la imprenta (McLuhan, 1985). Si el manuscrito conserva los modos audio- táctiles de la sensibilidad humana en un grado incompatible con la traducción de todos los sentidos, la Galaxia Guttenberg aniquila esa matriz de sensaciones imponiendo y trivializando la visión.

Por otro lado, conviene tener en cuenta, como explica Jay (2008), que una constelación de innovaciones técnicas, estéticas, políticas y sociales, surgidas a principio de la Era Moderna, contribuyeron a producir lo que se ha denominado la "racionalización de la vista". Estas innovaciones asumieron dos formas: la extensión del alcance y del poder del sistema ocular y el incremento de la capacidad de propagar los resultados de maneras accesibles a la vista, según este autor. A este respecto, las tecnologías de difusión, como la imprenta y otros instrumentos mecánicos, junto con la extensión tipográfica del ser humano posibilitada con anterioridad, dieron lugar a una ascendencia del sentido de la vista que tuvo múltiples repercusiones. Por ejemplo, apareció la aspiración de cuantificar visualmente aquello que no era visual, como el movimiento o la energía, siendo este el principio mismo de conocimiento aplicado. Pero, además, lo que caracterizó a la imprenta fue su mecanización y repetibilidad, factores que tuvieron repercusión en la ordenación de la sociedad. En efecto, el principio mecánico de la repetibilidad y la uniformidad visual, inherente a la imprenta, se extendió hasta incluir muchas formas de organización social, siendo esta apropiación la que condujo gradualmente a los modos de la producción y a las formas de administración de las gentes y de las cosas que caracterizan al mundo moderno (McLuhan, 1985). Es el caso, por ejemplo, de los sistemas panópticos de vigilancia que analizara Foucault (1985), resultado de un juego de miradas unidireccional (pues unos ven a otros y éstos no ven a aquellos), cada vez más presente en las calles y edificios de nuestras sociedades, que sustituyen al ver-y-ser-visto que se practica entre las gentes en su vida ordinaria (Bergua, 2002). Esta y otras "aplicaciones" del encumbramiento de tan reducida concepción de la visión están, pues, en la base de la producción de los individuos e incluso ciudadanos que pueblan nuestras sociedades en la modernidad.

Antes de estos cambios el mundo era distinto. Aunque hubiera libros y escritura, la lectura se realizaba en voz alta y la literatura estaba concebida para que fuera conversada con un auditorio. De hecho, partes de El Qui- 
jote están escritas instruyendo al lector sobre cómo comunicar con sus oyentes (Chartier, 1999, pp. 105 y ss.). La producción a gran escala, que trajo consigo la imprenta y la alfabetización generalizada de las gentes, propició una lectura silenciosa e individual que encajó en la sociedad moderna como la mano en un guante (Romanyshyn, 1993). En efecto, el radical encumbramiento de este tipo de vista, y la consiguiente ruptura de la sinestesia de los sentidos, sacrificó el ámbito de las emociones, empobreció las relaciones sociales y encumbró a un individuo, aislado, racional y afincado en un Yo que no ha cesado de crecer y, al paso, de exigir una desmesurada atención a base del creciente bazar de psicofármacos y psicoterapias que proliferan en nuestros días, seguramente porque un sujeto así no es posible que pueda sostenerse sin esas ayudas.

Por otro lado, la reducción de la experiencia a un solo sentido, el visual, como resultado de la tipografía y de la imprenta, dio lugar al punto de vista o a la posición fija y monológica que es tan habitual en el lector de textos tipográficos. Se consideró que, cuanto más estrechamente se limitan los datos para razonar acerca de algo, o estos vienen a través del mismo canal sensorial, más capaces somos de alcanzar la exactitud de nuestro razonamiento, a pesar de que, en realidad, este es mucho más restringido en su alcance. Tal énfasis en lo visual fue el paso preliminar y necesario para inventar el espacio unificado y la noción de perspectiva que utiliza la ciencia, modo de conocer que acostumbra a leer el mundo a través de un vasto conjunto de datos relativos a ciertos estándares de medida. Crary (1996) explica este nuevo punto de vista mediante el ejemplo de la cámara oscura. Este artefacto posicionaba al espectador, en una sala carente de luz, completamente descorporalizado e independiente de la representación. Por lo tanto, la cámara oscura implicó una supresión sistemática de la subjetividad, dado que el espectador queda en suspensión (incorpóreo) y separado del mundo observado. Tanto es así, que si algo se generó claramente con la escisión del sentido de la vista, fue la división entre el ojo, único sentido capaz de dar conocimiento, y el resto del cuerpo, retirado al plano de lo no medible, de lo no mesurable, de lo no real. Fue esta cabeza sin cuerpo, reflejo de la escisión de los sentidos, la que generó la supresión de la corporalidad en la tradición visual dominante en Occidente, dejando en el limbo una amplia gama de expe- riencias sensoriales, con sus particulares modos de explicar el mundo (Romanyshyn, 1993; Jay, 2003; Gómez, 2010).

\section{Ocularcentrismo en la arquitectura y el planeamiento urbano}

Como expresa Pallasmaa (2006), la hegemonía del ojo es un fenómeno bastante reciente, pues, como cita el autor, en opinión de Lucien Febvre, en el siglo XVI se tocaba, oía y olía mucho más abundante e intensamente que en la actualidad, y los sentidos correspondientes eran más importantes. A partir de entonces, fue cuando la vista puso su atención en el mundo de las formas con Kepler (1571-1630) y Desargues de Lyón (1593-1662). Por lo tanto, no fue hasta la Modernidad, cuando el ser humano desplegó su mirada en detrimento del resto de sentidos y comenzó así a mutilar el cuerpo y a encerrarse en un mundo más pequeño, homogéneo y pobre.

El ocularcentrismo, término que se ha utilizado para englobar a los discursos y prácticas en los que la visión goza de total hegemonía, ha sido el paradigma principal de la cultura occidental moderna y se ha aliado a la mayor parte de las tecnologías que nuestra época ha desplegado (Levin, 1993). El ocularcentrismo es, según Kavanagh (2004), un paradigma o una epistemología basada en el uso e imposición de metáforas visuales u oculares. Ha sido dominante, entre otros ámbitos, en la arquitectura, como refleja la teoría arquitectónica que se levantado desde Leon Battista Alberti, basada en la percepción visual, la armonía y la proporción (Pallasmaa, 2006). Por eso, el sentido de la vista es el predominante en los escritos de los arquitectos del movimiento moderno, como en los Le Corbusier (1999, citado en Pallasmaa, 2006), para quien "yo no existo, sino a condición de ver", o "solo se necesita ver claramente para entender".

Añade Pallasmaa, que la hegemonía de la visión ha dado lugar a una arquitectura narcisista y nihilista. Por una parte, la arquitectura se vuelve narcisista cuando se vuelve un juego intelectual y artístico de autoexpresión y se separa de las relaciones con otros ámbitos, valores e incluso juegos de la vida colectiva. Por otro lado, la arquitectura nihilista es aquella que, en lugar de reforzar la experiencia centrada en el cuerpo y la experiencia integrada del mundo, aísla el cuerpo y hace imposible una 
significación de carácter colectivo, provocando así que la arquitectura se convierta en un viaje visual carente de significado. Pero, además, este paradigma ocularcéntrico también ha tenido influencia en la planificación urbana. Los procesos de planeamiento han favorecido al ojo idealizado y descorporizado, siendo los principios funcionalistas de la zonificación y el planeamiento, así como las visiones altamente idealizadas y esquemáticas, reflejos de esta higiene óptica (idem). Por eso, también, el predominio de la visión en la arquitectura y el planeamiento urbano ha dado lugar a ciudades con edificios-imagen que adoptan la estrategia del marketing y de la publicidad (idem).

Aunque la teoría arquitectónica ha tendido a considerar el espacio como un objeto disociado de un sujeto, el espacio todavía exige que se le entienda a partir de las interacciones e interrelaciones dinámicas entre los propios sujetos y sus otras potencias sensoriales (De Certeau, 1990). Esto lo acepta en parte cierta arquitectura que concibe su obra como inseparable de la experiencia ampliamente entendida (Pallasmaa, 2006), pues no solo produce objetos, sino que relaciona, media y proyecta significados. Ya no estamos ante una colección de imágenes retinianas aisladas, sino ante experiencias arquitectónicas significativas, con encuentros e interacciones, que nos permite tener una experiencia de nosotros como seres corporales en el mundo. Entiende esta arquitectura que, cuando uno se acerca a un edificio, su cuerpo se aproxima, se encuentra, se relaciona con él y se mueve a través de él. El espacio, por lo tanto, es más un espacio vivido que un espacio físico y el espacio vivido se caracteriza por trascender la geometría y la mensurabilidad (idem). Este otro modo de entender el habitar que defiende cierta arquitectura tiene el mérito de reconciliarse con el habitar cotidiano y espontáneo de las gentes pues es también de esa clase. Por lo tanto, esta clase de arquitectura permite que lo instituido se reconcilie con las anónimas e indefinidas potencias instituyentes que activan las gentes

\section{Multicorporalidad y sinestesia de los sentidos}

Me siento a mí mismo en la ciudad y la ciudad existe a través de mi experiencia encarnada. La ciudad y mi cuerpo se complementan y se deben uno al otro. Habito en la ciudad y la ciudad habita en mí.

Maurice Merleau-Ponty, 2000.

La Postmodernidad, encabalgándose a una línea de fuga ya presente en la propia Modernidad, se caracteriza por desbordar el imperio de la visión (Hernández, 2007). El modelo de visión estable, fijo, inmóvil y descorporalizado de la "cámara oscura", comenzó a ser cuestionado en discursos filosóficos, científicos y tecnológicos que dieron importancia a una percepción fisiológica e insertada en el cuerpo (idem). Y, pese a que esta atención a lo corporal, en una primera etapa, puso al cuerpo como objeto de observación científica en el que verter su saber-poder, también puso en primer plano la subjetividad del observador, cuestionando al ojo desencarnado. Así fue como, de la mano de estos planteamientos y de las nuevas tecnologías de la postmodernidad, tuvo lugar la crisis del ocularcentrismo moderno.

Como expresa Howes (2014), le damos sentido al mundo, no solo con el lenguaje sino a través de nuestros sentidos y sus extensiones. Tradicionalmente, las prolongaciones de nuestros sentidos, herramientas y tecnologías $^{7}$, han sido sistemas cerrados e incapaces de interacción, pero en nuestra era electrónica, la instantaneidad y la coexistencia de dichas extensiones, de nuestros sentidos y de dichas tecnologías, ha requerido una interacción y coexistencia de nuestros sentidos corporales y

Sobre este asunto, como es de sobra conocido, el debate viene de lejos y es profundo. Según Heidegger (1994, pp. 9-37), quien representa el punto de vista más pesimista, la técnica, en tanto que poiesis, provoca en la naturaleza, sociedad, psique, etc., un desocultamiento destinado a suministrar energía o utilidad porque está en el ser del hombre su deseo de desocultar. Sin embargo, es posible que con su técnica y ciencia el hombre se equivoque con lo no oculto y lo malinterprete, lo cual hará que sea negado un hacer salir de lo oculto más originario y la exhortación de una verdad más original para que el hombre ingrese en la suprema dignidad de su esencia. Según Mumford (1998, p.66), la equivocación consiste en pensar que "renunciando a una parte considerable de su humanidad podría alcanzar la divinidad. Más optimista, Simondon (1989, pp. 241-266) dice que el objeto técnico es, ante todo, resultado de un acto de invención que exige habilidad para usarlo, pericia para repararlo y, en fin, un conocimiento profundo de su funcionamiento. En su opinión esta "tecnicidad" es una importante dimensión del ser. Finalmente, Sloterdijk opina que hay una rivalidad no resuelta entre la alotecnia (geométricamente abstracta y destinada a realizar actividades contranaturales -también contrasociales y contrasubjetivas-) y la homeotecnia (que colabora y coopera en términos de simbiosis con la naturaleza -lo social y lo subjetivo- (Sloterdijk y Heinrichs, 2004, pp. 136 y 323). 
de estos con sus extensiones tecnológicas. En general, cuando se introduce una tecnología en una cultura, se exterioriza un sentido que asciende y se externaliza en un medio que provoca la ruptura de la interacción y del equilibrio de los sentidos. Sin embargo, en nuestra era electrónica, puesto que simultáneamente se introducen masivamente nuevas tecnologías, la externalización de los sentidos es tan amplia y tan múltiple, que estos coexisten en plena interdependencia. Por lo tanto, si hasta ahora las extensiones tecnológicas de los sentidos han reforzado la hegemonía de la vista, con las nuevas tecnologías el cuerpo ha desplazado a la vista de su posición privilegiada y ha puesto en un primer plano la corporalidad ampliamente entendida, abriéndose así un mundo de sentidos interrelacionados.

El giro sensorial en la historia y la antropología tuvo lugar en la década de 1980. En esta época, se sucedieron trabajos que ponían en tela de juicio el visualismo del pensamiento y la cultura occidental, haciendo hincapié en la necesidad de trascender este sesgo con el fin de conectar con la experiencia cultural de los sujetos no occidentales (Howes, 2014). La antropología sensorial mostró cómo la experiencia sensorial está culturalmente ordenada, reconociendo la contingencia histórica de cualquier taxonomía de los sentidos (Howes, 2014, p. 17). Por eso los hausa de Nigeria distinguen entre gani o "vista" y $j i$, que incluye "escuchar, oler, gustar, palpar, entender y el sentir emocional. También en India el Brhadaranyaka Upanishad, sugiere una lista de ocho sentidos: 1) prana (órgano de respiración, i.e., la nariz; también "aliento de vida"); 2) el órgano del habla; 3 ) lengua (sabor); 4) ojo (color); 5) oído (sonidos); 6) mana (pensamiento, mente, órgano interno); 7) manos (trabajo); y 8) piel (sentido del tacto). De esta última taxonomía, cabe destacar la idea de la mente como un sentido, ya que se encuentra en oposición a la división entre mente y cuerpo, tan profundamente arraigada en occidente.

En términos sociológicos y políticos, teniendo en cuenta las diversas taxonomías de los sentidos en las distintas culturas, podemos decir que los sentidos son jerarquizados cuan- do a los grupos mayoritarios se les continúa asociando con unos sentidos "superiores" que proporcionan unas sensaciones consideradas "neutrales" (Howes, 2014). Esta desigualdad se fundamenta en el olvido o simplemente en la ignorancia de que ninguna descripción de los sentidos puede ser completa sin hacer mención a las diferencias sensoriales en razón del género, la etnia, la clase y, más importante aún, las diferencias corporales.

Ahora bien, dado que cada orden no es neutral sino construido culturalmente y que dicho orden se convierte en un orden político, también cabe que se activen, deliberada o espontáneamente, resistencias a dicho orden. Por eso hay desafíos protagonizados por personas o grupos que difieren de estos valores sensoriales (idem). Como explica Classen (citado en Howes, 2014), una técnica utilizada a este respecto ha sido la de la asignación de valores positivos a rasgos que han sido considerados de manera negativa, como, por ejemplo, el Black is beautiful, que contradijo los estereotipos de los cuerpos africanos como poco atractivos. Estos posicionamientos acerca de los marcadores sensoriales dieron lugar a un cuestionamiento del orden sensorial y social.

Del mismo modo, las personas que han sido discriminadas por su diversidad funcio$\mathrm{nal}^{8}$, se han reapropiado del término crip o "tullido" para subvertirlo y llenarlo de orgullo a la vez que para cuestionar los paradigmas de independencia, normalidad y medicalización (McRuer, 2006; Shakespeare, 2008; Guzmán y Platero, 2014; Taylor, 2017). Dicho cuestionamiento de la normalidad, pone el énfasis en las atribuciones que les han sido otorgadas a los cuerpos que no han entrado dentro de la construcción de lo normal y que han sido clasificados como deficientes o discapacitados. Haciendo una crítica a dichas categorías y desmontando su "naturalización", basada en la creación de normas o normalidades autojustificadas en simples mayorías estadísticas que convierten a ciertos cuerpos en deficientes, la resistencia crip se apoya en sus experiencias corporales para subvertir dichas atribuciones y poner el énfasis en la posibilidad de vivir el cuerpo de maneras diversas. Entre otras co-

Se refiere a personas que con diferentes características biofísicas y, dadas las condiciones de entorno, generadas por la sociedad, deben realizar las mismas tareas o funciones que el resto de la sociedad de manera diferente. Una misma función, una manera diversa de realizarla. "Este término considera la diferencia de la persona y la falta de respeto de las mayorías, que en sus procesos constructivos sociales y de entorno, no tiene en cuenta esa diversidad funcional." (Romañach y Lobato, 2007, p. 325). Dicho término fue acuñado por el Foro de Vida Independiente, en 2005, y actualmente es utilizado para referirse a la discapacidad en nuestro entorno. 
sas, esto implica que si el modo mayoritario de habitar la ciudad, encontrarse con un edificio y relacionarse con él, tiene que ver con sujetos reducidos a ojos, a su vez reducidos por la modernidad, por lo que tales sujetos están totalmente descorporalizados y carecen de interacción sensorial, es posible descubrir y/o provocara la aparición sujetos que, con sus experiencias encarnadas, muestren otros modos de habitar la ciudad y despierten así sus cualidades multisensoriales.

\section{Una acción multisensorial en la ciudad}

En la acción comunitaria, el papel del Trabajo Social es facilitar la participación, generando dinámicas colectivas que permitan ir construyendo una cultura cívica del espacio colectivo (Camps, 2000). Y en este papel, las trabajadoras sociales, como explica Navarro (2000), nunca han de acercarse al modelo "egológico" de intervención, en el que la relación es jerárquica sujeto-objeto, sino que han de convertirse en dispositivo de emancipación, mediante una relación horizontal sujeto-sujeto que es recíproca y que hace a sus participantes interdependientes en la transformación. Así, en la acción comunitaria, es imprescindible comprender el Trabajo Social no como un fin en sí mismo, sino como un medio (García y Rendueles, 2017), que no abogue por la intervención social jerárquica que viene de la ingeniería social, sino por una investigación participativa que tenga compromiso con la praxis; es decir: que sea herramienta de acción para transformar esas realidades (Fals Borda, 1993). A partir de estos compromisos nace, en 2015, el grupo de investigación-acción "mundoCRIP", con la intención de llevar a cabo acciones comunitarias a partir de la investigación participativa que hace posible indagar en las perspectivas que tienen los diversos sujetos, según sus experiencias en la ciudad, y que construyen conocimiento.

El colectivo "mundoCRIP", formado por cuerpos diversos del ámbito artístico, asociativo y universitario, ha llevado a cabo varias acciones para impulsar un habitar multicorporal en la ciudad de Zaragoza. De entre ellas, en esta ocasión expondremos brevemente la investigación-acción que este colectivo, gracias al Trabajo de Fin de Grado de Marcos Ruiz Pérez (2016), realizó en la ciudad de Zaragoza, con la intención de avivar un habi- tar más sensorial. Para ello, en primer lugar, caracterizaremos la intervención realizada en relación con la acción comunitaria que propone "mundoCRIP", poniendo el énfasis en la importancia de la participación que ha caracterizado este proceso. En segundo lugar, explicaremos la importancia que tiene intervenir para la comunidad, en general, en todo proceso comunitario y en relación a los objetivos de esta intervención y de "mundoCRIP”, en particular. $\mathrm{Y}$, por último, describiremos la metodología y ejecución de la intervención realizada a partir del Trabajo de Fin de Grado en Ingeniería de Diseño Industrial de Marcos Ruiz Pérez.

Como explican Llena y Úcar (2016), una acción comunitaria es aquella acción social que tiene lugar en el marco de una comunidad y que se distingue por ser interdisciplinar e interprofesional. El grupo “mundoCRIP”, así como las acciones que ha desarrollado, se caracterizan por aunar la participación e implicación de personas de distintas disciplinas y profesiones, como sucede en esta acción, en cuya iniciativa se involucran profesiones y disciplinas como la Ingeniería de diseño industrial, el Trabajo Social, el Arte o la Sociología, entre otras. Así mismo, la acción comunitaria, como su propio nombre indica, hace referencia al contexto de la comunidad, en el que la intervención se refiere a la "dinamización de relaciones sociales de cooperación entre los miembros de un determinado ámbito de convivencia en la ciudad" (Carmona y Rebollo, 2009, p.7). En nuestro caso, aunque la intervención que describimos a continuación se sitúa en un lugar concreto de la ciudad por las características físicas del espacio, el proceso participativo que tiene lugar en "mundoCRIP", aúna la dinamización de las relaciones entre personas de la ciudad de Zaragoza, no acotando la participación a los miembros de uno u otro barrio o espacio de la ciudad, pero sí buscando la mayor diversidad corporal que habita la ciudad.

Como ya mencionamos al inicio de este artículo, la participación es eje central y estratégico de la acción comunitaria y, por lo tanto, de la metodología de dicho proceso. Según explican Marchioni, Morín y Álamo (2013), dicha participación en estos procesos se sistematiza a partir de la teoría de los tres círculos, denominados "núcleo", "colaboradores parciales" e "informativo". El grupo "mundoCRIP" se inicia a comienzos de 2015 mediante reuniones periódicas de entre seis y ocho asistentes que constituirían el grupo "núcleo", o al que deno- 
minamos en su momento "grupo motor"9. Este grupo, que compondría el primer círculo según esta teoría, se compone de aquellas personas que toman la iniciativa de poner en marcha el proceso, garantizando el trabajo inicial. Entre mediados y finales de 2015, se decide invitar a participar a más gente, apareciendo así nuevos miembros en el círculo $1^{10}$ (personas que se incorporan al "grupo motor" o "núcleo"), y creándose los círculos 2 y 3 , grupo de "colaboradores parciales" e "informativo", respectivamente. Así, el "grupo motor", lo complementan, a partir de finales de 2015, un grupo de "colaboradores parciales" $" 11$ que participan en las sesiones y talleres, que se desarrollan una vez al mes hasta mediados de 2016, y que se compone de aquellas personas que, compartiendo los objetivos e intereses del "grupo motor" o "núcleo", participan en el proceso de manera provisional o discontinua; es decir, acudiendo a algunas (muchas o pocas) de las sesiones y los talleres que se llevan a cabo en este periodo. ${ }^{12}$ Mientras que el grupo "informativo" lo componen aquellos miembros que, no pudiendo o no queriendo participar del proceso, reciben la información del mismo con la premisa de que las situaciones cambian y pueden querer unirse a una participación activa en el proceso. El proceso de participación mediante reuniones y talleres se desarrolla hasta mediados de $2016 \mathrm{y}$, como todo proceso de participación es dinámico, tal dinamismo también se ve reflejado en las situaciones de las personas que forman este proceso, dándose incorporaciones y abandonos en cada uno de los círculos ${ }^{13}$.
Como explican Marchioni, Morín y Álamo (2013), la acción comunitaria es una propuesta interesante y necesaria para cualquier territorio o comunidad que no necesariamente ha de encontrarse en una situación crítica o de necesidad. O lo que es lo mismo, como dicen estos autores, la acción comunitaria es necesaria y realizable también para la población en general, haciendo posible el papel activo de la ciudadanía. Por ello, si bien en esta acción atendemos en el proceso de investigación a ciertos sujetos, cuyas experiencias en la ciudad escasamente son tenidas en cuenta (personas con diversidad funcional), la ejecución de dicha acción se planifica, organiza y realiza teniendo en cuenta el interés que puede suscitar para la población en general, dado que la finalidad de la intervención realizada se dirige a cualquier habitante de la ciudad de Zaragoza que desee probar dicho experimento. Con ello, precisamente, damos cabida a lo que este experimento participativo puede suponer en la diversidad funcional. Un giro ontológico ${ }^{14}$ que alberga la misma y que no se refiere a la tradicional posición asistencialista de intervenir para aportar/adaptar a la diversidad funcional, sino, al contrario, aportar a la población en general, diversas maneras de habitar la ciudad desde las perspectivas que "otros" cuerpos tienen en los espacios que habitan. Y de esta manera, con la apertura que supone atender a "otras" perspectivas de habitar la ciudad, facilitar contar con ellas a la hora de construir ciudad. Por lo tanto, la intervención que aquí se describe se encuentra en sincronía con los propósitos de "mundoCRIP", entendiendo que de lo que se trata es

$9 \quad$ El impulso de este proyecto y que, por lo tanto, forman en su inicio el "grupo motor", viene de la mano de docentes e investigadores de las áreas de Trabajo Social y Servicios Sociales y de Sociología de la Universidad de Zaragoza, así como de una artista, experta creativa, los cuales inician este proceso mediante reuniones mensuales, que comienzan en febrero de 2015, y que tienen por finalidad discutir y reflexionar acerca de paradigmas de diversidad funcional, creatividad, arte como herramienta de transformación social, participación, urbanismo, etc.

10 Algunas de las personas invitadas a colaborar se muestran muy interesadas en el proyecto "mundoCRIP", por lo que deciden implicarse en mayor grado y pasan a formar parte del grupo motor o "núcleo". Es el caso de personas relacionadas con el ámbito asociativo, el artístico, el activismo, la arquitectura o la ingeniería de diseño industrial, que junto con el grupo motor inicial, se reúnen cada quince días, entre diciembre de 2015 y junio de 2016, para elaborar los contenidos se las sesiones mensuales con el grupo de "colaboradores".

11 Este grupo se inicia con la asistencia de 20 personas de los ámbitos asociativo, artístico, universitario, económico y político-administrativo. Sin embargo, estos dos últimos ámbitos quedan escasamente representados en las sesiones participativas, puesto que su afluencia a las mismas es menor, por lo que pasan a formar parte del grupo "informativo". Pese a que la afluencia de los miembros del grupo de "colaboradores parciales" varía de una sesión a otra, esta suele rondar las 12-18 personas.

12 Las sesiones y talleres que tienen lugar mensualmente, entre diciembre de 2015 y junio de 2016, pueden consultarse en el siguiente blog: http://mundocrip.blogspot.com/

13 Para conocer con más detalle el proceso participativo que tuvo lugar dentro de "mundoCrip" atendiendo a la sistematización de la práctica en Trabajo Social, léase Gargallo (2016).

14 Nos referimos al "giro ontológico" entendiéndolo como una herramienta metodológica que no somete al "otro" a los marcos de referencia del pensamiento moderno occidental, aceptando las ontologías propias de este "otro", con la finalidad de producir conocimiento (Henare, Holbraad y Wastell, (2007, citado en Grados, 2015). Es decir, buscando conocer la perspectiva de ese "otro" o, como diría Pink (2009, citado en Grados, 2015), su "cosmopercepción". 
de poner encima de la mesa las diversas percepciones que tienen los sujetos de la ciudad y de su habitar, no reproduciendo categorizaciones dicotómicas como "capacitado"-“discapacitado", sino, más bien, desarrollando procesos de investigación-acción que cuestionen estos conceptos mediante las perspectivas de sujetos con diversas condiciones corporales y mentales ${ }^{15}$.

Para esta acción, partimos de una muestra de carácter estructural (De Lucas, 1995, pp. 109 y ss.), que constaba de seis colaboradores que formaban parte del grupo "mundoCRIP" y que cruzaban representación de varias variables: distintos tipos de diversidad funcional (auditiva, visual, intelectual, mental y físico-orgánica), grado de diversidad funcional (alta, media, baja), si es adquirida o congénita, edad, género y distrito (distinguiendo 6 zonas de la ciudad en total). A esta muestra, aplicamos el Cultural Probes (Ruiz Pérez, 2016, p. 16), en el que la creatividad es la herramienta principal que permite conocer las actividades cotidianas de las personas en contextos reales. En concreto, el participante se convierte en reportero de su actividad diaria y elabora un diario centrándose en un objetivo determinado. Los participantes, preferiblemente mediante vídeo pero también con mensajes de texto, audio o dibujos (según fuese accesible para cada persona), exponen una escena en la que muestran con un pos-it aquello que les parece positivo o negativo en su interacción con el entorno urbano ${ }^{16}$. De entre estas ideas seleccionamos de modo participado una, intentando cumplir nuestro objetivo principal: hacer de Zaragoza una ciudad más habitable en términos multicorporales. En concreto se decidió prestar atención a un sujeto con diversidad visual, que decía "escuchar las paredes". Se refería al hecho de escuchar el sonido que rebota en las paredes y que, de esta forma, le permite orientarse, saber dónde acaba la calle o notar dónde hay garajes o huecos en las paredes. Por lo tanto, mediante este método descubrimos, entre otras, esta experiencia corporal. A partir de ahí, de lo que se trata es de discutir la intervención más adecuada y desarrollarla.
Así, el trabajo de fin de grado también utilizó, teniendo en cuenta esa experiencia seleccionada, la metodología Journey Mapping con la cual exploramos todas las posibilidades que nos ofrecía la ciudad.

Esta metodología, permite que la persona se ponga en el lugar de los vecinos, desde distintos puntos de la ciudad, y que experimente qué se siente al caminar y pararse por parques, plazas y calles. Con esta metodología y con el objetivo de llamar la atención y convocar a la participación, seleccionamos una zona de gran afluencia de personas situada en el Casco Viejo de Zaragoza. Igualmente elegimos una zona colindante, más reducida y con abundantes estructuras sólidas que facilitasen el juego de sonoridades.

Finalmente, la intervención también utilizó de un modo participado la técnica Storyboard (Ruiz Pérez, 2016, p.18). Puesto que nuestra idea de intervención era dinamizarla a base de retroalimentación, decidimos complementar la acción con la reacción que produce en los protagonistas y en el entorno la exposición de viñetas, dibujos o narraciones que retratan y desarrollan los resultados o efectos de la estimulación y de las posteriores respuestas.

La culminación de todos estos pasos fue la construcción de un prototipo. Se trata de un dispositivo que, mediante ultrasonidos, detecta la posición del usuario al rebotar la señal en un obstáculo. Una vez registrada la señal, esos datos se usan para convertir en una señal acústica la distancia restante hasta el obstáculo. Para ello, el dispositivo emplea sonidos cortos y agudos con una frecuencia concreta. Cuanto más cerca se encuentre el usuario del obstáculo, más alta será esa frecuencia, de forma que el usuario obtiene así la posibilidad de controlar su distancia hasta el mismo

El principal objetivo del prototipo es materializar, de un modo participado y en diferentes pasos, el deseo de invitar a los habitantes de Zaragoza, en principio a quienes estaban cierto día y hora en el lugar elegido -pero la idea es ampliar espacial y temporalmente la invitación- a relacionarse con el espacio de una manera distinta a como lo hacen habitual-

15 Por primera vez en este texto se hace referencia a la dicotomía cuerpo-mente con la intención de visibilizar que no solo nos estamos refiriendo a las condiciones corporales, si no que se albergan estos mismos planteamientos también para las diversas condiciones mentales. No obstante, simplemente se hace referencia a esta dicotomía para aclarar lo dicho, puesto que, nos referimos a lo "corporal", en el sentido de que son nuestros cuerpos los que habitan los espacios y no hay en ellos una división entre cuerpo, percepción y emoción (Escribano, 2012).

16 Los seis colaboradores tuvieron tres días para enviar al menos tres escenas en las que contasen dichas experiencias en interacción con el entorno urbano. 
mente, activando otras funciones corporales y, sobre todo, otra organización de las distintas funciones. Teniendo en cuenta que, como se explicó anteriormente, la arquitectura y el planeamiento urbano, han privilegiado al ojo descorporeizado, desligado del resto de sentidos corporales, esta intervención intentó desvincular el habitar de la ciudad de una percepción únicamente visual y desatar así una sinestesia de los sentidos. En concreto, se prestó atención al sonido (el que desprende el dispositivo y el propio del entorno), pero también al tacto (de los obstáculos del recorrido) y al olfato (del ambiente, característico de dichas calles del Casco Viejo). Pero es que, además, las personas que participaron, confesaron sentirse entusiasmadas al encontrar más formas de relacionarse con el entorno (Ruíz Pérez, 2016). En fin, que alejarse de las formas normalizadas de relación es una forma de placer o de diversión.

\section{Conclusiones}

La interacción de los sentidos y su externalización en forma de tecnologías nos posibilitan la relación con el entorno, dando significado a este y a nosotros dentro del mismo, pero cuando se da ascendencia a uno de nuestros sentidos, la sinestesia y la interdependencia entre ellos, se rompe y esto puede servir de anestésico a los demás sentidos.

En la Modernidad, las innovaciones tecnológicas como la imprenta, de carácter repetible $\mathrm{y}$ uniforme, favorecieron el predominio del sentido visual y la ruptura de la sinestésica. Más tarde, con la incorporación de las tecnologías modernas que han seguido priorizando lo visual se ha producido una división entre el ojo (descorporeizado y objetivo, único capaz de dar conocimiento) y el resto de sentidos corporales y subjetivos. Todo este complejo tecnológico, aunque en alianza con otras influencias socioculturales, también ha estimulado el aislamiento del individuo moderno, ya que la vista nos separa del mundo, mientras que el resto de sentidos nos acerca a él.

El ocularcentrismo resultante, plenamente instalado en la modernidad y postmodernidad, se caracteriza por ser un paradigma o epistemología en el que la visión, que goza de total hegemonía, se ha vuelto dominante en múltiples ámbitos. Entre otros, la arquitectura y el planeamiento urbano. Efectivamente, la arquitectura, tanto en su vertiente teórica como en la práctica, ha tenido como criterio fundamental la percepción, proporción y armonía visual. Por su parte, el planeamiento urbano ha partido también de ese ojo desencarnado para disponer los usos y funciones de la ciudad.

Sin embargo, la arquitectura y la ciudad, no son simple ni realmente una colección de imágenes o lugares por los que transitar atendiendo únicamente a la percepción visual. Lo que distingue a la arquitectura de otras artes es la posibilidad de interactuar, por lo que la reacción corporal es un aspecto inseparable de la experiencia arquitectónica. En efecto, cuando uno se acerca a un edificio, su cuerpo se aproxima, se encuentra, se relaciona con él y se mueve a través de él. El espacio, por lo tanto, es un espacio vivido más que un espacio para ser visto.

Ahora bien, ¿cuáles son las consecuencias de que la visión haya sido desplazada por otra clase de tecnologías como ocurre en la actualidad? Si hasta ahora las herramientas y tecnologías modernas y postmodernas han sido prolongaciones que han reproducido la hegemonía de sistemas cerrados, incapaces de interacción, en la actualidad, gracias a las tecnologías de la información, se ha estimulado una interacción y coexistencia de nuestros sentidos corporales entre sí y de todos ellos con sus extensiones tecnológicas.

Por otro lado, que la experiencia sensorial esté cultural y socialmente jerarquizada, quedando ocultado o en estado latente el carácter construido (y, por lo tanto, contingente) de tal o cual jerarquía, implica también el hecho de que los grupos mayoritarios son asociados a unos sentidos "superiores" y que, una vez borrado el carácter contingente de esa superioridad, tales sensaciones sean consideradas "neutrales".

Afortunadamente, puesto que cada orden social es construido, es lógico que haya resistencias no solo espontáneas o no del todo conscientes, sino también con una voluntad de cambio deliberada. En concreto, existen desafíos protagonizados por personas o grupos que difieren de los valores sensoriales convertidos en hegemónicos. Se ha utilizado una técnica de resistencia: la de asignar valores positivos a los rasgos tradicionalmente considerados como negativos. En este sentido, la reapropiación de la palabra crip ("tullido", "tarado", etc.) por unas personas discriminadas por su diversidad funcional, ha subvertido la jerarquía haciendo que esa posición subalterna se llene de orgullo. 
Esta resignificación ha dado lugar a distintas clases de cuestionamiento del orden.

Si vivimos en una época que cada vez más decididamente trata de desmontar bastantes de los presupuestos fundacionales de la Modernidad, ¿cómo no desmontar las categorías estancas y las normas que definen de un modo tan estrecho la salud? y ¿cómo no discutir las interacciones de nuestros sentidos y de estos con las distintas tecnologías?

En este artículo, hemos resumido como ejemplo de ello un original e innovador proyecto de Trabajo Fin de Grado que, mediante el uso de las tecnologías como formas de externalización de nuestros sentidos, nos permite la interacción e interdependencia de nuestros sentidos. Dicho proyecto tuvo por objetivo facilitar, de un modo participado y en varias fases, que las personas intervinientes en la acción tuvieran la posibilidad de experimentar cómo nuestros sentidos, externalizados en formas de tecnologías, nos permiten habitar los espacios de maneras diversas, y cómo se genera una amplia gama de experiencias de los cuerpos en el entorno. Con ello, damos ca- bida al giro ontológico desde las perspectivas de sujetos con diversas condiciones corporales (en este caso concreto, sensoriales), las cuales producen conocimiento y que transformamos en acción, con la intención de cuestionar los planteamientos dicotómicos tan arraigados en nuestra cultura occidental.

La acción comunitaria, lleva en su génesis, transformar la sociedad en la que vivimos. A menudo, la acción social se enfoca hacia intervenciones jerárquicas y asistenciales para resolver necesidades de aquellos que han sido clasificados como "esos", "otros", "discapacitados". Sin embargo, en la acción social, no se suele atender al carácter más estructural de estas relaciones de poder y que derivan, entre otras cuestiones, de las dicotomías que clasifican a ese "otro" y que niegan sus experiencias y perspectivas. Precisamente, es a partir de la investigación participativa iniciada en "mundoCRIP", la que ha hecho posible atender a estas perspectivas, que producen conocimiento, y el cual se convierte en herramienta de acción en la praxis de la acción comunitaria.

\section{Referencias bibliográficas}

Asaro, P.M. (2000).Transforming society by transforming technology: the science and politics of participatory design. Accounting Management and Information Technology, 10, 257-290.

Bergua, J.A. (2002). La gente contra la sociedad. Zaragoza: Mira.

Bergua, J.A. (2011). Estilos de la investigación social. Técnicas, epistemología, algo de anarquía y una pizca de sociosofia. Zaragoza: Prensas Universitarias.

Bergua, J.A. (2017). Sociosofia. Barcelona: Anthropos.

Bourriaud, N. (2006). Estética relacional. Buenos Aires: Adriana Hidalgo Editora.

Camps, F. (2000). Participación comunitaria y gestión alternativa de conflictos. Cuadernos de Trabajo Social, 15, 231-251.

Carmona, M. y Rebollo, O. (coord.) (2009). Guia Operativa d'Acció Comunitària. Barcelona:

Ayuntamiento de Barcelona.

Chartier, R. (1999). El mundo como representación. Barcelona: Gedisa.

Crary, J. (1996). Techniques of the Observer. Cambridge: The MIT Press.

Danto, A.C. (2012). Después del fin del arte. El arte contemporáneo y el linde de la historia. Barcelona: Paidós.

De Certeau, M. (1990). L'invention du quotidien, 1. Arts de faire. París: Gallimard.

Demo, P. (2009). Investigación participante. Mito y realidad. Buenos Aires: Lumen-Humanitas.

De Lucas, A. (1995). Memoria de oposición a plaza de Titular de Escuela Universitaria. Madrid: Universidad Complutense (inédito).

Di Siena, D. (2011). Ciudades de Código Abierto. Hacia nuevos modelos de gobernanza local. Recuperado de: http://www.laciudadviva.org/blogs/?p=10801

Dienell, P.C. y Harm, H. (2001). Repensar la democracia. Los Núcleos de Intervención Participativa. Barcelona: Serbal.

Escribano, A. (2012). Sociología de los cuerpos/emociones. Revista Latinoamericana sobre Cuerpos, Emociones y Sociedad, 10, 93-113. 
Fals Borda, O. (1993). La investigación participativa y la intervención social. Documentación Social, 92, 9-22.

Foucault, M. (1985): Vigilar y castigar, Madrid: Siglo XXI.

García, S. y Rendueles, C. (2017). Hacia un nuevo trabajo social crítico. El gobierno de lo social en la era neoliberal. Presentación del monográfico. Cuadernos de Trabajo Social, 30(2), 243-260.

Gargallo, E. (2016). ROMPIENDO ESTIGMAS. La Sistematización de la Praxis desde el Trabajo Social. [Trabajo Fin de Grado de Trabajo Social. Universidad de Zaragoza]. Disponible en: https://zaguan. unizar.es/record/62829/files/TAZ-TFG-2016-4960.pdf

Grados, C.G. (julio 2015). Antropología y ceguera. Posibilidades de una aproximación desde el giro ontológico (Comunicación presentada I Congreso AIBR "El ser humano: culturas, orígenes y destinos". Madrid).

Genro, T. y Souza, U. (2000). El Presupuesto Participativo. Barcelona: Ediciones El Serbal.

Gómez López-Quinones, A. (2010).Visibilidad variable en el documental: los límites del ocularcentrismo en Invisibles. Bulletin of Hispanic Studies, 87(2), 242-257.

Guzmán, F. y Platero, R.L. (2014). The critical intersections of disability and non-normative sexualities in Spain. Annual Review of Critical Psichology, 11, 359-387.

Heidegger, M. (1994): Conferencias y Artículos, Barcelona: Serbal-Guitard.

Hernández Navarro, M.A. (2007). El archivo escotómico de la modernidad. Pequeños pasos para una cartografía de la visión. Madrid: Ayuntamiento de Alcobendas.

Hess, R. y Savoye, A. (dir.) (1988). Perspectives de l'Analyse Institutionelle. París: Meridiens Klincsieck.

Hess, Ch. y Ostrom, E. (2011). Introduction. En: Ch. Hess y E. Ostrom (eds.). Understanding knowledge as a Commons. From Theory to Practice (pp. 3-26). Cambridge: The MIT Presss.

Holm, I. (2006). Ideas and Beliefs in Architecture and Industrial design: How attitudes, orientations, and underlying assumptions shape the built environment. Oslo: School of Architecture and Design.

Howes, D. (2014). El creciente campo de los Estudios Sensoriales. Revista Latinoamericana de Estudios sobre Cuerpos, Emociones y Sociedad, 15, 10-26.

Ibáñéz, J. (1985). Del algoritmo al sujeto. Perspectivas de la investigación social. Madrid: Siglo XXI.

Irigaray, L. (1978). Entrevista. En: Les femmes, la pornographie et l'erotisme. París: M.-F. Hans y G. Lapouge.

Jay, M.(1988). Scopic Regimes of Modernity. En: Hal Foster (ed.), Vision and Visuality. Discussions in Contemporary Culture (2). Nueva York: Bay Press.

Jay, M. (2003). Devolver la mirada. La respuesta americana a la crítica francesa al ocularcentrismo. Estudios visuales: Ensayo, teoría y crítica de la cultura visual y el arte contemporáneo, 1, 60-81.

Jay, M. (2007). ¿Parresía visual? Foucault y la verdad de la mirada. Estudios visuales: Ensayo, teoría y crítica de la cultura visual y el arte contemporáneo, 4, 7-22.

Jay, M. (2008). Ojos abatidos. La denigración de la visión en el pensamiento francés del siglo XX. Madrid: Akal.

Jenks, Ch. (1995).The Centrality of the Eye in Western Culture: An Introduction. En: Ch. Jenks (ed.), Visual Culture (pp. 1-25). Londres y Nueva York: Routledge.

Kavanagh, D. (2004). Ocularcentrism and its Others: A Framework for Metatheoretical Analysis. Organization Studies, 25(3), 445-464.

Laddaga, R. (2010). Estética de la emergencia. Buenos Aires: Adriana Hidalgo Editora.

Laister, J. y Lipphardt, A. (2015). pARTiCI(TY)pate?! Negotiating the City at the Intersection of Art, Research and Urban Politics. Anthropological Journal of European Cultures, 4(2), 3-15.

Levin, D.M. (1988). The Opening of Vision. Nihilism and the Postmodern Situation. Londres: Routledge.

Levin, D.M. (1993). Modernity and the Hegemony of Vision. Berkeley: University of California Press.

Llena, A. y Úcar, X. (2006). Acción comunitaria: miradas y diálogos interdisciplinares, En: Úcar, X. y Llena, A. (coords.), Miradas y diálogos en torno a la acción comunitaria (pp.11-57). Barcelona: Graò.

Marchioni, M., Morin, L. y Álamo, J. (2013). Metodología de la intervención comunitaria. Los procesos comunitarios. En: J. Buades y C. Giménez, Hagamos de nuestro barrio un lugar habitable. Manual de intervención comunitaria en barrios (pp.58-73). Valencia: Tirant Lo Blanch.

McLuhan, M. (1985). La Galaxia Guttenberg. Barcelona: Planeta-Agostini.

McRuer, R. (2006). Crip Theory: Cultural signs of Queerness and Disability. Nueva York: New York University Press.

Merleau-Ponty, M. (2000). Fenomenología de la percepción. Península: Barcelona. 
Mumford, L. (1998). Técnica y civilización. Madrid: Alianza.

Navarro, S. (2000). Contra los puentes levadizos: la formación de trabajadores sociales en clave comunitaria. Cuadernos de Trabajo Social, 15, 183-202.

Pallasmaa, J. (2006). Los ojos de la piel. Barcelona: Gustavo Gili.

Precarias a la Deriva et al. (2004). De preguntas, ilusiones, enjambres y expertos. Apuntes sobre investigación y militancia desde Precarias a la Deriva, Posse, Derive Approdi (et al.), Nociones comunes. Experiencias y ensayos entre investigación y militancia (pp. 81-92). Madrid: Traficantes de Sueños.

Ranciére, J. (2008). L'expectateur émancipé. Paris: La Fabrique Éditions

Rheingold, H. (2002). Multitudes inteligentes. La próxima revolución social. Barcelona: Gedisa.

Rifkin, J. (2014). La sociedad de coste marginal cero. Barcelona: Paidós.

Romanyshyn, R.D. (1993).The Despotic Eye and Its Shadow: Media Image in the Age of Literacy. En: D.M. Levin (ed.) (1993), Modernity and the hegemony of vision (pp. 339-360). Berkeley: University of California Press.

Romañach, J. y Lobato, M. (2007). Diversidad funcional. Nuevo término para la lucha por la dignidad de la diversidad del ser humano. En: L. Álvarez Pousa, et al. (coord.), Comunicación y discapacidades. Actas del Foro Internacional. Galicia: Observatorio Gallego de Medios. Colegio profesional de Periodistas de Galicia.

Ruiz Pérez, M. (2016). Diseño y planificación de una acción de intervencionismo urbano sobre el colectivo Crip de personas con diversidad funcional. (Trabajo Fin de Grado en Ingeniería de diseño industrial y desarrollo de producto. Universidad de Zaragoza). Recuperado de: http://zaguan.unizar.es/record/61068

Simondon, G. (1989). Du mode d'existence des objets techniques. Paris: Aubier.

Sloterdijk, P. y Heinrichs, H.J. (2004). El sol y la Muerte. Madrid: Siruela.

Shakespeare, T. (2008). La autoorganización de las personas con discapacidad, ¿Un nuevo movimiento social? En: L. Barton (coord.), Superar las barreras de la discapacidad (pp. 68-85). Madrid: Ediciones Morata.

Taylor, S. (2017). Beasts of burden. Animal and disability liberation. NuevaYork: New York University Press.

Tylor, S. (1991). Acerca de la descripción-desescritura como un hablar por. En: C. Gerrtz, J. Clifford, et al., El surgimiento de la antropología postmoderna. Barcelona: Gedisa.

VV.AA. (1995). La Investigación-Acción-Participativa(IAP). Cuadernos de la Red, 3. Número monográfico. Madrid: Red CIMAS 